\title{
Penerapan Bahan Ajar Bahasa Indonesia bagi Penutur Asing (BIPA) "Sahabatku Indonesia" Tingkat Dasar di IAIN Surakarta
}

\author{
Dwi Kurniasih *), Siti Isnaniah \\ Institut Agama Islam Negeri (IAIN) Surakarta \\ *) Corresponding author: Jl. Pandawa, Dusun IV, Pucangan, Kec. Kartasura, Kabupaten Sukoharjo, \\ Jawa Tengah 57168, Phone:(0271) 781516, Indonesia \\ e-mail: dwikurniasih445@gmail.com
}

\begin{abstract}
This study aims to describe the application of basic level BIPA Sahabatku Indonesia teaching materials at IAIN Surakarta. The method used in this research is descriptive qualitative. The method is used to describe and explain the basic level of BIPA Sahabatku Indonesia teaching materials used in BIPA learning at IAIN Surakarta. This research requires direct study in the field to get optimal results. The place chosen to conduct research is at the BIPA institution in IAIN Surakarta which has a new BIPA institution for foreign students. Data sources are classified into two parts, namely informants and events. The results showed in the BIPA learning process in Surakarta IAIN the main teaching material used was Indonesian Friends of Primary and A1 in each class. The learning process of using teaching materials runs well and is structured according to the contents of the book. However, textbooks that are more appropriate to be used at PTKIN are still needed so that the learning objectives can run optimally. Special BIPA SKL is needed for PTKIN so that learning outcomes are in accordance with the right goals and have a clear handle, especially in the realm of Islamic Studies.
\end{abstract}

Keywords: Teaching Materials, BIPA, IAIN Surakarta

This work is licensed under a Creative Commons Attribution-ShareAlike 4.0 International License

\section{Pendahuluan}

Bahasa Indonesia bagi Penutur Asing (BIPA) adalah salah satu program pelatihan dan pendampingan untuk penutur asing dalam rangka peningkatkan fungsi bahasa negara sebagai bahasa internasional dan pemenuhan kebutuhan tenaga kerja asing pada program pelatihan bahasa Indonesia (Kurniawan, Ambarwati, Batubara, Hermina, \& Larasati, 2019: 14). Lembaga pengajaran BIPA di dalam negeri dapat dilaksanakan di Perguruan Tinggi (PT) yang memiliki program darmasiswa ataupun PT yang terdapat mahasiswa asing yang sedang menempuh studi di Indonesia. Hampir setiap PT di Indonesia negeri maupun swasta memiliki lembaga BIPA, baik Perguruan Tinggi Umum (PTU) ataupun Perguruan Tinggi Keagamaan Islam Negeri (PTKIN). PTKIN merupakan PT yang berada di bawah Kementrian Agama. Di lingkup Kementrian Agama terdapat empat Perguruan Tinggi yang memiliki lembaga BIPA dan telah menyelenggarakan pembinaan bahasa bagi mahasiswa asing. Di antara empat PT tersebut ialah UIN Maulana Malik Ibrahim Malang, UIN Sunan Kalijaga Yogyakarta, UIN Syarif Hidayatullah Jakarta, dan Institut Agama Islam Negeri Surakarta (Ulfiana, 2017).

BIPA di IAIN Surakarta termasuk lembaga baru yang didirikan atas dasar Keputusan Rektor IAIN Surakarta Nomor 95 Tahun 2017 tentang Pendirian Program Bahasa Indonesia bagi Penutur Asing (BIPA) di IAIN Surakarta. Berdirinya BIPA di IAIN Surakarta dapat menjadi ruang bagi mahasiswa asing untuk mempelajari bahasa Indonesia sebelum kuliah di IAIN Surakarta.

Berdirinya lembaga BIPA di IAIN Surakarta menuntut terbentuknya sistem pembelajaran bahasa Indonesia yang terstruktur dan terencana. Dengan demikian, dibutuhkan kurikulum BIPA yang tepat, materi ajar menyeluruh, tenaga pengajar mumpuni, dan sarana prasarana yang 
memadai guna tercapai keberhasilan pada proses pembelajaran BIPA. Perangkat pembelajaran yang mendukung efektivitas belajar bahasa Indonesia bagi orang asing salah satunya adalah bahan ajar (Qomariyah, 2018: 2). Oleh karena itu, kesiapan Perguruan Tinggi di lingkup PTKIN khususnya, dalam penyelenggaraan BIPA ini perlu dimaksimalkan dalam segala hal, baik sumber daya manusia pengajar BIPA, sarana dan prasarana, termasuk metode maupun bahan ajar.

Ketersediaan bahan ajar BIPA di IAIN Surakarta masih sangat terbatas pada buku teks yang dikeluarkan oleh Badan Pengembangan Bahasa dan Perbukuan Kementerian Pendidikan dan Kebudayaan. Penggunaan bahan ajar yang minim dapat berpengaruh pada proses pembelajaran bahasa. Semakin banyak modul yang digunakan, maka semakin baik pula proses penerimaan bahasa kedua bagi penutur asing. Sebaliknya, apabila sumber belajar terbatas, maka kebutuhan bahasa bagi penutur asing masih belum tercukupi dengan baik.

Keterbatasan tersebut menjadi kendala serius yang kerap dihadapi pembelajar BIPA. Pembelajar BIPA mengalami kesulitan dalam memilih materi yang tepat untuk membantu penutur asing dalam mencapai kompetensi. Materi ajar BIPA yang sesuai dengan tujuan program BIPA memiliki manfaat yang cukup besar bagi program BIPA itu sendiri.

Selain kebutuhan pada aspek empat keterampilan berbahasa, penutur Asing di IAIN Surakarta yang notabene adalah mahasiswa sangat memerlukan adanya pembelajaran bahasa Indonesia yang memuat unsur Islamic Studies. Mengingat, pembelajaran atau perkuliahan di IAIN Surakarta adalah pembelajaran yang sarat dengan kajian-kajian keislaman.

Dari pemaparan tersebut, penulis tertarik untuk meneliti bahan ajar BIPA Sahabatku Indonesia tingkat dasar yang digunakan di lembaga BIPA IAIN Surakarta. BIPA tingkat dasar dipilih dengan pertimbangan bahwa, tingkat dasar menjadi proses awal orang asing mempelajari bahasa Indonesia. Tidak hanya itu, BIPA tingkat dasar di lingkup Perguruan Tinggi merupakan program awal sebelum orang asing resmi menjadi mahasiswa sehingga kebutuhan materi ajar harus disesuaikan dengan yang diharapkan oleh orang asing. Kemudian, jumlah penutur asing di tingkat dasar sering kali lebih banyak dari pada di tingkat selanjutnya, sebab program untuk tingkat dasar di IAIN Surakarta dilakukan secara intensif.

Lembaga BIPA di IAIN Surakarta termasuk lembaga yang dibawahi oleh Kementrian Agama yakni Perguruan Tinggi Keagamaan Islam (PTKI) sehingga lembaga tersebut memiliki keunikan dibanding lembaga BIPA yang berdiri di Perguruan Tinggi Umum dalam hal Islamic Studies. Maka perlu ada sinkronisasi antara pengajaran bahasa Indonesia yang mencakup empat keterampilan berbahasa dengan konsep nilai-nilai Islam yang disajikan dalam pembelajaran BIPA, khususnya di IAIN Surakarta. BIPA IAIN Surakarta dipilih sebagai objek penelitian karena tergolong lembaga baru yang berdiri di bawah Kemenag. Kemudian, dari empat PTKIN yang menyelenggarakan program BIPA, hanya IAIN Surakarta yang statusnya masih institut, akan tetapi telah memiliki program BIPA.

Pembelajaran BIPA memiliki perbedaan dengan pengajaran bahasa Indonesia yang berkedudukan bahasa pertama (B1). Pembelajaran BIPA lebih kompleks dan pelik, hal tersebut disebabkan penutur asing yang belajar bahasa Indonesia berasal dari berbagai negara (Muliastuti, 2017: 17). Pelajar BIPA merupakan pelajar yang memiliki bahasa pertama dan berlatar belakang budaya yang berbeda (Fariqoh, 2016: 219).

Pembelajaran BIPA termasuk dalam pembelajaran bahasa kedua (Jazeri 2016; Hapsari, Sutama, dan Wendra, 2017). Bahasa kedua yang dianggap memiliki struktur yang berbeda menyebabkan sulit untuk dipahami oleh pembelajar. Kesulitan orang asing dalam untuk memahami bahasa kedua terjadi karena beberapa faktor, yaitu metode pembelajaran, struktur B2, lingkungan, serta motivasi pelajar (Wahyono \& Yashinta Farahsani, 2017: 205).

Menurut Suyitno (2005: 10), pembelajaran BIPA pada hakikatnya adalah sebuah aktivitas yang sistemis, sistematis, dan terencana. Sistemis karena di dalamnya terdapat seperangkat aspek 
dan serangkaian kegiatan yang saling berkaitan. Disebut sistematis karena dalam pelaksanaanya bersifat prosedural. Terencana karena pembelajaran sudah tergambar dengan jelas dan tegas.

Pembelajaran BIPA memiliki dua aspek, yakni aspek instruksional dan aspek kondisional (Muliastuti, 2017: 18). Aspek instruksional mencakup: (1) tujuan pembelajaran; (2) materi pembelajaran, (3) metode pembelajaran; (4) media belajar; (5) pengelolaan kelas; (7) pemelajar; (8) pengajar. Aspek kedua adalah aspek kondisional yang meliputi: (1) pengondisian kesiapan akan kebutuhan pemelajar; (2) pengupayaan pemajanan dan kewacanaan dalam situasi kebahasaan yang sesungguhnya; (3) pengondisian suasana pembelajaran; (4) pengupayaan pelatihan mandiri (Suyitno, 2005:11-16).

Penelitian tentang BIPA yang membahas bahan ajar dan pembelajaran BIPA pernah dilakukan oleh (Prasetiyo, 2015) dalam skripsi dengan judul Pengembangan Bahan Ajar BIPA Bermuatan Budaya Jawa bagi Penutur Asing Tingkat Pemula. Hasil dari penelitian yang dilakukan oleh (Prasetiyo, 2015) menunjukkan bahwa berdasarkan analisis kebutuhan penutur asing beserta pengajar BIPA karakteristik bahan ajar BIPA bermuatan budaya Jawa bagi penutur asing tingkat pemula, ragam bahasa mudah dimengerti, terdapat motivasi, dan terdapat teknik latihan empat keterampilan bahasa, terdapat soal kebahasaan pada masing-masing bab.

Persamaan penelitian yang akan dilakukan dengan penelitian milik (Prasetyo, 2015) adalah dalam hal membahas bahan ajar BIPA beserta pembelajarannya. Bahan ajar yang diteliti adalah untuk tingkat dasar. Akan tetapi, penelitian tersebut memiliki berbedaan yakni pada bahan ajar yang diteliti. Penelitian yang akan dilakukan difokuskan pada bahan ajar BIPA Sahabatku Indonesia tingkat dasar yang dikeluarkan oleh Badan Pengembangan dan Pembinaan Bahasa Kementerian Pendidikan dan Kebudayaan.

Penelitian serupa dengan penelitian ini ialah milik (Agustina, 2013) dalam tesisnya dengan judul Implementasi Pembelajaran Bahasa Indonesia bagi Penutur Asing di UPT P2B Universitas Sebelas Maret Surakarta. Hasil penelitian ialah tentang persepsi pengajar terhadap pembelajaran BIPA dan kendala-kendala dalam pembelajaran BIPA yang diklasifikasikan dalam tiga sumber kesulitan yakni, keperluan atau kesibukan mendesak pengajar, penyampaian terlalu cepat, bahasa pengantar di awal pertemuan, waktu, serta sarana prasarana. Perbedaan penelitian ini dengan penelitian milik (Agustina, 2013) adalah penelitian ini mengkaji penerapan bahan ajar BIPA Sahabatku Indonesia tingkat dasar dalam proses pembelajaran BIPA di IAIN Surakarta. Maka, fokus penerapan hanya pada kegiatan pembelajaran menggunakan bahan ajar tersebut.

Berdasarkan pemaparan tersebut, penelitian ini akan membahas penerapan bahan ajar BIPA "Sahabatku Indonesia" tingkat dasar di IAIN Surakarta. Penelitian ini akan melihat proses pembelajaran BIPA di IAIN Surakarta dengan bahan ajar yang dikeluarkan oleh PPSDK.

\section{Metode}

Metode penelitian yang digunakan ialah deskriptif kualitatif. Deskripstif kualitatif adalah metode yang berusaha menjelaskan objek dengan sebenarnya dan apa adanya. Metode tersebut akan digunakan dalam menjelaskan proses pembelajaran BIPA di IAIN Surakarta yang menggunakan bahan ajar tersebut.

Sumber data diklasifikasikan menjadi dua bagian yakni, informan dan peristiwa. Informan yang dipilih adalah informan yang berpengaruh pada pengambilan informasi yang hendak dikaji secara mendalam. Informan dari penilitian ini adalah ahli BIPA, pengajar BIPA IAIN Surakarta, tutor BIPA IAIN Surakarta dan mahasiswa asing yang belajar bahasa Indonesia di IAIN Surakarta. Sumber data peristiwa bertujuan untuk mengetahui terjadinya sesuatu dengan pasti dan jelas. Dalam hal ini, peristiwa yang dimaksudkan adalah proses pembelajaran BIPA untuk tingkat dasar lembaga BIPA IAIN Surakarta. Teknik pengumpulan data ialah cara memperoleh data yang dibutuhkan untuk menjawab suatu masalah (Moleong, 2000:58). Teknik pengumpulan data menggunakan wawancara secara mendalam (in depth interview), dan peristiwa/observasi. 


\section{Pembahasan}

\section{Perencanaan Pembelajaran BIPA}

Perencanaan pembelajaran BIPA pada hakikatnya ialah persiapan yang dilakukan pengajar sebelum pembelajaran berlangsung. Kegiatan perencanaan pembelajaran meliputi proses penyusunan materi, penggunaan media, strategi yang akan diguanakan, metode, dan penilaian yang dilakukan untuk mencapai tujuan yang akan dicapai. Agar dapat menyusun perencanaan pembelajaran yang baik, pengajar harus menguasai kurikulum, menguasai materi atau bahan ajar, menyusun dan melaksanakan program pembelajaran serta melakukan penilaian.

Berdasarkan hasil wawancara dengan tutor BIPA di IAIN Surakarta terkait perencanaan pembelajaran, maka perencanaan pembelajaran yang terdapat di IAIN Surakarta ialah RPS (Rencana Pembelajaran Semester). RPS disusun oleh tim BIPA yang terdiri dari dosen dan mahasiswa yang mengambil konsentrasi mata kuliah BIPA di IAIN Surakarta. RPS yang disusun telah disesuaikan dengan Standar Kelulusan (SKL) BIPA berdasarkan pada Permendikbud nomor 17 tahun 2017.

Meskipun RPS disusun secara bersama oleh tim, akan tetapi terkait pengembangan materi yang akan disampaikan tergantung pada kreativitas masing-masing pengajar. Hal ini disebabkan masing-masing pengajar memberikan materi pada bidangnya masing-masing yaitu keterampilan menyimak, membaca, berbicara, menulis, kebudayaan Indonesia, dan wawasan keislaman.

Perencanaan pembelajaran BIPA di IAIN Surakarta hanya sebatas pada RPS tiap semester dan tidak menggunakan Rencana Pembelajaran (RP) di setiap pertemuan.Hal ini menunjukkan bahwa perencanaan pembelajaran di BIPA IAIN Surakarta kurang sempurna karena hanya sebatas pada RPS, sedangkan dalam proses pembelajaran dibutuhkan RP untuk mengoptimalkan kelangsungan pembelajaran yang lebih detail.

\section{Pelaksanaan Pembelajaran BIPA}

Pada pelaksanaan pembelajaran terdapat beberapa aspek yang digunakan oleh pengajar BIPA yakni, materi, metode, media, dan strategi pembelajaran BIPA. Berikut penjelasan masingmasing aspek pelaksanaan pembelajaran BIPA.

\section{Materi Pembelajaran}

Keberhasilan dalam proses pengajaran dan pembelajaran sangat ditentukan oleh kemampuan pengajar dalam merancang materi pengajaran. Materi yang diberikan pengajar hendaknya sesuai dengan kebutuhan pemelajar, sesuai dengan tingkat kemampuan pemelajar, bersifat kontekstual. Berdasarkan hasil wawancara dengan pengajar BIPA di IAIN Surakarta, materi pengajaran yang diberikan untuk mahasiswa asing bersumber pada buku ajar BIPA Sahabatku Indonesia sesuai dengan tingkatnya.

Alasan penggunaan buku ajar Sahabatku Indonesia di BIPA IAIN Surakarta, pertama buku tersebut mengacu pada standar kualifikasi bahasa atau CEFR yang merupakan standar pembelajaran bahasa asing yang digunakan di Eropa. Kedua, pihak BIPA IAIN Surakarta telah melakukan kerjasama dengan Badan Pengembangan Bahasa dan Perbukuan yang membawahi PPSDK untuk menggunakan buku tersebut sebagai bahan ajar.

Sebelum proses pembelajaran berlangsung para pengajar melakukan placement test terhadap mahasiswa asing untuk menyesuaikan kemampuannya dengan kelas yang akan ditempuh yakni kelas pemula, menengah, dan lanjut. Semua mahasiswa asing yang masuk di lembaga BIPA IAIN Surakarta kemampuannya termasuk ke dalam pemula, sehingga buku ajar yang digunakan adalah tingkat A1 dan A2.

Sebelum pembelajaran BIPA berlangsung, tim BIPA IAIN Surakarta telah melakukan dialog terkait tujuan mahasiswa asing belajar bahasa Indonesia di IAIN Surakarta. Mayoritas 
jawaban mereka adalah untuk melanjutkan studi S-1 di IAIN Surakarta sehingga mereka dapat berbahasa Indonesia secara baik dan benar di lingkungan akademik dan nonakademik. Secara tertulis, mereka mampu membuat tugas berupa artikel atau penelitian, bisa mengisi identitas, mengirim pesan singkat. Hal tersebut menunjukkan bahwa materi yang diberikan menyesuaikan kebutuhan mahasiswa asing.

Sejauh ini, selain menggunakan bahan ajar dari PPSDK, BIPA IAIN Surakarta juga menggunakan bahan ajar yang dikelola dan diterbitkan oleh lembaga BIPA IAIN Surakarta. Buku tersebut bukan sebagai buku utama akan tetapi buku pendamping berupa modul. Buku pendamping tersebut telah disesuaikan dengan latar belakang mahasiswa asing dari Thailand yang homogen.

Sementara itu, proses pembelajaran BIPA IAIN Surakarta memiliki ciri khas yang tidak semua lembaga BIPA memiliki kekahasan tersebut, yakni pada materi Islamic Studies. Usaha untuk memasukan unsur Islamic Studies dalam pembelajaran BIPA dengan menggunakan buku pendamping Meneroka Bahasa dan Budaya Indonesia, Tim BIPA IAIN Surakarta telah memasukkan unsur budaya dan wawasan keislaman di dalamnya sebagai buku pendamping setelah buku ajar BIPA Sahabatku Indonesia.

Berdasarkan hasil wawancara dengan salah satu pengajar BIPA terkait bahan ajar untuk wawasan keislaman ialah, bahan ajar Sahabatku Indonesia pada saat pembelajaran tidak banyak digunakan. Hanya mengambil beberapa materi yang memiliki keterkaitan dengan Islam di Jawa. Jika materi dalam buku ajar Sahabatku Indonesia tidak memuat topik yang akan disampaikan saat pembelajaran, maka pengajar membuat materi sendiri tentang wawasan Islam khususnya di Jawa. Lingkup pembelajaran wawasan keislaman fokus pada Islam di Jawa khususnya Surakarta. Pembuatan materi wawasan keislaman dilatarbelakangi karena jika hanya menggunakan buku tersebut maka materi masih kurang sesuai.

Kemudian fokus ajar wawasan keislaman berkaitan dengan budaya Islam lokal maka harus mengambil materi dari luar buku Sahabatku Indonesia. Respon dari mahasiswa asing cukup baik ketika belajar tentang sejarah Islam di Jawa khususnya Surakarta. Hal ini ditunjukkan antusiasme mahasiswa asing saat berkunjung ke Keraton Surakarta.

Buku ajar BIPA Sahabatku Indonesia secara keseluruhan apabila digunakan untuk mengajarkan bahasa Indonesia dan wawasan keindonesiaan sudah cukup memenuhi standar kompetensi yang dibutuhkan oleh penutur asing. Namun, apabila mengajar dalam konteks memberikan wawasan Islam maka perlu mencari materi tambahan dari sumber lain.

Tujuan pokok yang hendak dicapai dari kelas wawasan keislaman adalah mahasiswa asing tinggal di Solo dan selama empat tahun studi secara tidak langsung mereka akan mengamati fenomena keberagaman yang ada di Solo. Tujuan ketika mengajar materi tersebut adalah agar mereka tidak merasa asing dengan budaya-budaya lokal di Solo sehingga ketika mereka berbaur dengan masyarakat tidak mengalami kebingungan atau shock culture.

\section{Metode Pembelajaran BIPA}

Metode pembelajaran ialah salah satu aspek dalam pelaksanaan pembelajaran yang tidak mungkin dihilangkan atau diabaikan. Dengan demikian, dibutuhkan metode pembelajaran yang beragam dengan tujuan agar pemelajar tidak mengalami kejenuhan ketika pembelajaran berlangsung. Metode yang digunakan pengajar cenderung menuntut pemelajar untuk lebih aktif. Metode dasar yang kerap digunakan ialah ceramah. Ceramah digunakan untuk membangun konsep awal pemahaman akan materi yang hendak dipelajari. Selain ceramah, metode lain yang digunakan meliputi tanya jawab, presentasi, diskusi, demonstrasi/pemeragaan model.

Berdasarkan hasil observasi pelaksanaan pembelajaran BIPA di IAIS Surakarta maka metode yang digunakan cenderung bervariasi. Artinya pengajar BIPA tidak hanya bertumpu pada satu metode saja. Penggunaan metode pembelajaran yang bervariasi didasarkan pada pertimbangan atau menyesuaikan keadaan di lapangan dan pemelajar di kelas. Metode 
pembelajaran yang bervariasi juga merupakan salah satu usaha pengajar untuk memotivasi pemelajar dalam pembelajaran.

\section{Media Pembelajaran BIPA}

Media dibutuhkan saat pelaksanaan pembelajaran berlangsung. Saat pelaksanaan pembelajaran diperlukan suatu alat atau media yang bertujuan untuk mempermudah penyampaian materi pembelajaran kepada pemelajar. Media pembelajaran bertujuan untuk mempermudah dan membuat peserta didik termotivasi selama mengikuti pembelajaran. Media yang digunakan sebaiknya menyesuaikan dengan materi yang akan diberikan.

Berdasarkan hasil observasi saat pelaksanaan pembelajaran BIPA di IAIN Surakarta media yang digunakan cenderung bervariasi seperti layar proyektor, media tulis, video, gambar, makanan tradisional, dan banyak jenisnya menyesuaikan dengan materi yang hendak disampaikan. Penggunaan media disesuaikan dengan materi yang akan disampaikan. Penggunaan media merupakan salah satu upaya untuk membuat pemelajar semangat dalam belajar dan tidak mudah jenuh.

\section{Strategi Pembelajaran BIPA}

Strategi yang diterapkan adalah strategi yang inovatif dan menyenangkan. Strategi yang inovatif merupakan salah satu upaya untuk menumbuhkan karakter pemelajar. Strategi yang digunakan saat pembelajaran BIPA di IAIN Surakarta berupa strategi kooperatif dengan membuat tim atau kelompok-kelompok kecil, strategi ekspositori dengan fokus pada proses penyampaian materi secara verbal dari seseorang guru ke sekelompok siswa. Hal ini bertujuan supaya siswa mampu menguasai materi dengan optimal. Kemudian, strategi inquiry adalah rangkaian kegiatan pembelajaran yang menekankan siswa berpikir secara kritis dan analitis.

Berdasarkan hasil wawancara dengan tutor BIPA di IAIN Surakarta maka strategi yang digunakan saat pelaksanaan pembelajaran cenderung bervariasi. Strategi pembelajaran yang digunakan oleh pengajar BIPA disesuaikan dengan situasi dan keadaan pemelajar. Dengan demikian, proses pembelajaran tidak bergantung pada satu strategi saja.

\section{Evaluasi/Penilaian Pembelajaran}

Evaluasi pembelajaran adalah usaha untuk mengukur kemampuan pemelajar dalam pembelajaran dengan efektif. Dalam pembelajaran, evaluasi tidak hanya dilakukan saat ujian akhir semester saja. Evaluasi dapat dilakukan secara harian yakni saat pembelajaran berlangsung usai melalui tanya jawab misalnya, dapat juga dilakukan secara mingguan, dan di akhir semester.

Penilaian proses yang dilakukan oleh pengajar saat pembelajaan dilakukan secara integratif pada masing-masing kelas. Penilaian proses yang dilakukan tidak terpisah antara keterampilan satu dengan yang lain. Pada proses pembelajaran dilakukan penilaian secara praktik. Praktik merupakan salah satu cara yang baik digunakan oleh pengajar karena dengan praktik pengajar akan mengetahui kemampuan pemelajar secara baik dan objektif.

Berdasarkan hasil wawancara dengan pengajar BIPA di IAIN Surakarta, maka kegiatan evaluasi secara keseluruhan dilakukan di akhir semester dengan melaksanakan ujian baik tertulis ataupun lisan. Hasil evaluasi dibuktikan dengan sertifikat yang menyatakan lulus dan naik tingkat atau sebaliknya.

\section{Penerapan Bahan Ajar BIPA Sahabatku Indonesia Tingkat Dasar di IAIN Surakarta}

Proses pembelajaran BIPA untuk tingkat dasar di IAIN Surakarta menggunakan buku ajar BIPA Sahabatku Indonesia untuk tingkat dasar yaitu A1 dan A2. Sesuai dengan pemetaan kompetensi kurikulum BIPA dari PPSDK dan buku ajar Sahabatku Indonesia, maka dijabarkan dalam bentuk Rencana Pembelajaran Semester (RPS). RPS tersebut telah disesuaikan dengan ciri khusus BIPA di IAIN Surakarta, yaitu dengan menambahkan wawasan budaya dan keislaman 
dengan buku pendamping Meneroka Bahasa dan Budaya Indonesia yang disusun oleh tim BIPA IAIN Surakarta. Satuan pembelajaran semester dirincikan kembali melalui Rencana Pelaksanaan Pembelajaran (RPP) atau dalam istilah BIPA disebut juga Rencana Pembelajaran (RP).

Seperti proses pembelajaran pada umumnya, pembelajaran BIPA melalui beberapa tahap pembelaharan yaitu perencanaan, pelaksanaan dan evaluasi. Perencanaan pembelajaran berkaitan dengan kesiapan materi, bahan ajar, fasilitas seperti tempat, media yang akan digunakan. Sementara itu, pelaksanaan berkaitan dengan metode pembelajaran, strategi pembelajaran, dan model pembelajaran. Kemudian, evaluasi berkaitan dengan penilaian setelah pembelajaran berlangsung. Evaluasi dapat dilakukan harian yakni saat pembelajaran berlangsung usai melalui tanya jawab misalnya, dapat juga dilakukan secara mingguan, dan di akhir semester.

\section{Perencanaan Pembelajaran BIPA}

Berdasarkan hasil observasi proses pembelajaran BIPA di IAIN Surakarta dalam hal perencanaan berfokus pada buku ajar Sahabatku Indonesia tingkat dasar. Tim BIPA IAIN Surakarta juga menyusun RPS berdasarkan buku ajar tersebut dan memuat $12 \mathrm{x}$ pertemuan. Dalam hal perencanaan metode dan media pembelajaran pengajar menyesuaikan materi yang hendak disampaikan. Jadi, masing-masing materi dalam RPS berbeda.

\section{Pelaksanaan Pembelajaran BIPA}

Pelaksanaan pembelajaran merupakan proses implementasi dari perencanaan pembelajaran yang telah disusun. Dalam proses pelaksanaan pembelajaran terdapat tiga aspek meliputi, pendahuluan, kegiatan inti, dan penutup. Berikut aspek kegiatan pelaksanaan pembelajaran BIPA di IAIN Surakarta berdasarkan hasil observasi 1 pada Selasa, 21 Mei 2019.

\section{Pendahuluan}

Berdasarkan hasil observasi pada pembelajaran BIPA kelas membaca di IAIN Surakarta maka kegiatan pendahuluan dapat dijelaskan sebagai berikut. Pemelajar merespon salam tanda mensyukuri anugerah Tuhan. Sebelum pembelajaran berlangsung pengajar menyiapkan kondisi pemelajar mulai dari kesiapan psikis maupun fisik dalam mengikuti kelas membaca dengan memanggil nama pemelajar berdasarkan urutan presensi.

Pemelajar memperoleh informasi dengan aktif keterkaitan pembelajaran sebelumnya dengan pembelajaran yang akan berlangsung. Pemelajar mendapatkan informasi kompetensi, materi, tujuan, manfaat, dan langkah pembelajaran yang akan dilaksanakan. Pemelajar mengambil undian dengan nomor 1, 2, 3. Pemelajar berelompok berdasarkan nomor yang sama.

\section{Kegiatan Inti}

Pemelajar membaca teks tentang Pasar Beringharjo (data 9). Pemelajar mencermati isi teks dengan disiplin. Pemelajar bertanya jawab dengan proaktif tentang kosakata yang baru saja diketahui dengan disiplin. Pemelajar berdiskusi menetukan maksud dan tujuan dalam teks yang telah dibaca. Pengajar memberi kesempatan pada pemelajar berdasarkan berkelompok untuk mengolah informasi yang didapat dari hasil kegiatan sebelumnya. Hal ini bertujuan untuk memperluas, memperdalam, mencari solusi dari masalah tentang maksud dan tujuan yang terkandung dalam teks. Pemelajar memberikan kesempatan kepada masing-masing kelompok untuk memverifikasi sehingga dapat menemukan maksud yang terkandung. Pemelajar menyusun laporan dan peserta didik dapat memaparkan hasil diskusi tentang maksud yang terkandung dalam teks. 


\section{Penutup}

Pemelajar dan pengajar menyimpulkan materi yang telah dipelajari tentang teks bacaan dan makna yang terkandung. Pemelajar melakukan refleksi pembelajaran yang telah berlangsung dengan mencatatan penguasaan materi. Pemelajar mengerjakan evaluasi berkaitan dengan materi yang telah disampaikan. Pemelajar bertukar pekerjaan dan mengoreksi pekerjaan kemudian memberi umpan balik hasil evaluasi. Pemelajar mendapat tugas untuk mencari teks yang mengandung informasi tentang keindonesiaan.

Berdasarkan penjelasan terkait proses pembelajaran BIPA di IAIN Surakarta khususnya pada kelas membaca, maka dapat tarik kesimpulan bahwa pembelajaran terfokus pada bahan ajar Sahabatku Indonesia untuk tingkat dasar. Proses pembelajaran dari awal hingga akhir menggunakan bahan ajar tersebut. Sedikit ataupun banyak pembelajaran tersebut mampu meningkatkan kemampuan berbahasa khususnya pada keterampilan membaca. Dengan demikian, buku tersebut mampu memberi pengetahuan kebahasaan kepada penutur asing meskipun masih terdapat istilah-istilah yang sulit dipahami untuk tingkat pemula.

Kemudian observasi kedua pada pembelajaran BIPA di IAIN Surakarta ialah pada kelas berbicara. Pembelajaran tersebut dilaksanakan dilakukan di dalam dan luar kelas. Berikut proses pembelajaran BIPA di IAIN Surakarta pada kelas berbicara pada Rabu, 19 Juni 2019.

\section{Pendahuluan}

Proses pembelajaran BIPA di IAIN Surakarta pada kelas berbicara diawali dengan pengajar mengucapkan salam tanda mensyukuri anugerah Tuhan. Sebelum pembelajaran berlangsung pengajar menyiapkan kondisi pemelajar mulai dari kesiapan psikis maupun fisik dalam mengikuti kelas berbicara dengan memanggil nama pemelajar berdasarkan urutan presensi.

Pemelajar mendapat informasi secara aktif keterkaitan pembelajaran sebelumnya dengan pembelajaran yang akan dilaksanakan. Pemelajar menerima informasi tentang kompetensi, materi, tujuan, manfaat, dan langkah pembelajaran yang akan berlangsung.

\section{Kegiatan Inti}

Pengajar memberikan prolog dengan bertanya kepada pemelajar terkait jenjang pendidikan di Indonesia (data 17). Kemudian memberikan kesempatan kepada pemelajar untuk bertanya terkait topik tersebut. Setelah pemelajar memahami maksud dan tujuan yang terdapat pada bahan ajar BIPA Sahabatku Indonesia.

Setelah itu, pengajar meminta pemelajar untuk mencari informan untuk diwawancarai terkait program studi yang ditempuh oleh satu mahasiswa di IAIN Surakarta. Mahasiswa yang menjadi sasaran ialah yang menempuh program studi yang sama dengan program studi yang ingin diambil oleh pemelajar.

Daftar pertanyaan dibuat sendiri oleh pemelajar. Pengajar hanya memberikan kata kunci untuk ditanyakan kepada informan. Setelah pemelajar melakukan wawancara singkat, maka pemelajar melakukan presentasi di depan kelas untuk menceritakan hasil wawancaranya. Hal tersebut bertujuan untuk meningkatkan kemampuan berbahasa pemelajar khususnya pada keterampilan berbicara.

\section{Penutup}

Pemelajar dan pengajar menyimpulkan materi yang diajarkan. Pemelajar melakukan refleksi tentang pembelajaran yang berlangsung dengan mencatat penguasaan materi. Pemelajar mengerjakan evaluasi berhubungan dengan materi yang telah 
disampaikan. Pemelajar bertukar pekerjaan dan mengoreksi pekerjaan kemudian memberikan umpan balik hasil evaluasi.

\section{Evaluasi Pembelajaran BIPA}

Evaluasi merupakan bagian pentingg dari hasil akhir suatu proses pembelajaran yang telah dilakukan. Evaluasi pembelajaran berupa pemantauan, penilaian, dan pelaporan hasil belajar pemelajar selama kurun waktu tertentu. Proses penilaian dapat berupa harian, mingguan, dan akhir semester.

Berdasarkan hasil observasi pada pembelajaran BIPA di IAIN Surakarta maka setiap pertemuan selalu ada evaluasi berupa tanya jawab secara lisan maupun tulis. Sementara itu, evaluasi pada akhir semester dilakuakn secara tertulis pada masing-masing kelas dan berupa lisan. Hasil evaluasi dibuktikan dengan dikeluarkanya sertifikat kelulusan dan kenaikan tingkat selanjutnya.

Tes uji dalam rangka evaluasi melingkupi semua kelas yang ada di IAIN Surakarta yakni menyimak, membaca, berbicara, menulis, wawasan keislaman dan budaya. Di bidang keterampilan berbahasa tes telah disesuaikan dengan SKL dari Permendikbud nomor 17 tahun 2017. Akan tetapi, pada uji wawasan keislaman dan budaya belum terdapat SKL yang paten, sehingga diperlukan SKL BIPA khusu untuk PTKIN agar hasil pembelajaran sesuai dengan tujuan yang tepat dan memiliki pegangan yang jelas.

\section{Simpulan}

Pada proses pembelajaran BIPA di IAIN Surakarta bahan ajar utama yang digunakan adalah Sahabatku Indonesia untuk tingkat dasar A1 dan A2 di masing-masing kelas. Proses pembelajaran BIPA menggunakan buku ajar tersebut berjalan dengan baik dan terstruktur sesuai isi buku yang meliputi perencanaan, pelaksanaan, dan evaluasi pembelajaran BIPA. Artinya materi terkait keterampilan berbahasa dapat disampaikan dengan optimal. Dalam penyusunan bahan ajar tersebut telah disesuaikan dengan kurikulum BIPA dan SKL BIPA sesuai Permendikbud nomor 17 tahun 2017. Akan tetapi, tetap dibutuhkan buku ajar yang lebih tepat digunakan di PTKIN agar tujuan pembelajaran dapat berjalan dengan optimal.

\section{Daftar Rujukan}

Agustina, R. (2013). Implementasi Pembelajaran Bahasa Indonesia bagi Penutur Asing di UPT P2B Universitas Sebelas Maret Surakarta. Universitas Sebelas Maret.

Fariqoh, R. (2016). Pengembangan Bahan Ajar Membaca untuk Pembelajar Bahasa Indonesia Penutur Asing Tingkat Dasar. Riksa Bahasa, 2(2), 219-223.

Hapsari, Y. R., Sutama, I. M., \& Wendra, I. W. (2017). Pelaksanaan Pembelajaran BIPA Siswa Kelas XI di Gandhi Memorial Intercintinental School Bali. E-Journal Universitas Pendidikan Ganesha, 6(1), 1-13.

Jazeri, M. (2016). Model Perangkat Pembelajaran Keterampilan Berbicara Dengan Pendekatan Komunikatif Kontekstual Bagi Mahasiswa Asing. Jurnal LITERA, 15(2), 217-226.

Kurniawan, Ambarwati, D., Batubara, D. H., Hermina, \& Larasati. (2019). Pelaksanaan Program BIPA dan Hasil Pembelajarannya. JBIPA, 1(1), 11-21.

Moleong, L. J. (2000). Metode Penelitian Kualitatif. Bandung: Remaja Rosdakarya.

Muliastuti, L. (2017). Bahasa Indonesia bagi Penutur Asing. Jakarta: Yayasan Obor Indonesia.

Prasetiyo, A. E. (2015). Pengembangan Bahan Ajar BIPA Bermuatan Budaya Jawa bagi Penutur Asing Tingkat Pemula. Universitas Negeri Semarang.

Qomariyah, N. W. (2018). Pengembangan Bahan Ajar Membaca BIPA untuk Tingkat Pemula dengan Pendekatan Kontekstual. Universitas Muhammadiyah Malang. 
Suyitno, I. (2005). Bahasa Indonesia untuk Penutur Asing: Teori, Strategi, dan Aplikasi Pembelajarannya. Yogyakarta: Grafika Indah.

Ulfiana, E. (2017). Di era MEA Bahasa Indonesia Menempati Posisi Strategis, IAIN Surakarta Menjadi Bagian Dari Empat Penyelenggara Lembaga BIPA Di PTKIN Seluruh Indonesia. Retrieved from http://www.iain-surakarta.ac.id/?p=7714

Wahyono, T., \& Yashinta Farahsani. (2017). Penerapan Pendekatan Proses untuk Meningkatkan Keterampilan Berbicara Bahasa Indonesia bagi Penutur Asing. AKSIS: Jurnal Pendidikan Bahasa Dan Sastra Indonesia, 1, 204-220. 